Table 2

Matrix of Correlations Between Variables of Table 1

\begin{tabular}{|c|c|c|c|c|c|c|c|c|c|}
\hline Variable & $\mathbf{f}_{\mathfrak{p}}$ & $\mathrm{N}_{\mathrm{D}}$ & $\mathbf{M}$ & I & $\mathbf{S}$ & $\mathrm{C}$ & $\mathbf{F}$ & $\mathbf{P}$ & $\mathbf{N}_{\mathbf{N}}$ \\
\hline L & -.05 & .00 & -.09 & -.11 & .09 & .16 & -.14 & .20 & .24 \\
\hline $\mathbf{f}_{\mathbf{p}}$ & & $-.83^{* *}$ & $.53^{* *}$ & $.65^{* *}$ & $.40^{*}$ & $.46^{* *}$ & $.56 * *$ & $-.44^{* *}$ & .26 \\
\hline$N_{D}$ & & & -.28 & $-.53^{* *}$ & $-.38^{*}$ & $-.37^{*}$ & $-.48 * *$ & .29 & -.15 \\
\hline$M^{2}$ & & & & $.68^{* *}$ & $.55^{* *}$ & .70 & $.55^{* *}$ & $-.63 * *$ & $.50^{* *}$ \\
\hline I & & & & & $.77^{* *}$ & $.83^{* *}$ & $.86^{* *}$ & $-.57 * *$ & $.35^{*}$ \\
\hline$S$ & & & & & & $.87^{* *}$ & $.62^{* *}$ & $-.54 * *$ & $.56^{* *}$ \\
\hline $\mathrm{C}$ & & & & & & & $.72 * *$ & $-.60^{* *}$ & $.53^{* *}$ \\
\hline $\mathbf{F}$ & & & & & & & & $-.50 * *$ & .22 \\
\hline $\mathbf{P}$ & & & & & & & & & $-.54 * *$ \\
\hline
\end{tabular}

Table 3

Rotated Matrix of Principle Components with Labels; Attributes with Appreciable Loadings on a Component in Italics

\begin{tabular}{|c|c|c|c|c|c|c|c|}
\hline \multirow{2}{*}{ Attribute } & \multicolumn{7}{|c|}{ Component } \\
\hline & $\mathrm{S}, \mathrm{C}$ & $\mathrm{f}_{\mathrm{p}}, \mathrm{N}_{\mathbf{D}}$ & $\mathbf{L}$ & $\mathbf{N}_{N}$ & $\mathbf{M}$ & $\mathbf{P}$ & $\mathrm{F}$ \\
\hline $\mathbf{L}$ & .06 & -.01 & -.98 & .11 & -.04 & -.09 & -.06 \\
\hline $\mathbf{M}$ & .30 & .18 & .07 & .22 & .84 & .24 & .22 \\
\hline$f_{p}$ & .10 & .87 & .02 & .09 & .31 & .14 & .24 \\
\hline $\mathbf{N}_{\mathrm{D}}$ & -.20 & -.95 & .00 & -.02 & .03 & -.06 & -.13 \\
\hline I & .57 & .37 & .10 & .08 & .33 & .15 & .58 \\
\hline S & .88 & .19 & -.04 & .27 & .12 & .16 & .22 \\
\hline C & .74 & .17 & -.16 & .18 & .34 & .24 & .38 \\
\hline $\mathbf{F}$ & .37 & .29 & .09 & .03 & .16 & .16 & .83 \\
\hline $\mathbf{P}$ & -.27 & -.17 & -.15 & -.27 & -.24 & -.84 & -.19 \\
\hline $\mathbf{N}_{\mathbf{N}}$ & .27 & .07 & -.15 & .90 & .18 & .22 & .04 \\
\hline
\end{tabular}

(SS) and Paivio, Yuille, \& Madigan (PYM) did not obtain values for $\mathrm{F}$ or $\mathrm{N}_{\mathrm{N}}$. Nor did they report primaries, $f_{p}$, and $N_{D}$. The $S S$ means for $M, S, C$, and $P$ and the $P Y M$ means for $M, I$, and $C$ are shown in the last and next-to-last rows, respectively. Means for $M$ and $\mathrm{C}$ obtained for the words of Table 1 are less than the SS and PYM means. The means for $S$ and $P$ are close to the SS mean; the mean for I is below the PYM mean.

$I, S$, and $C$ each enter significant correlations with every other measure, except L (Table 2). $M, f_{p}, F$, and $P$ each appear in correlations with seven of the nine other measures, with $\mathrm{L}$ always excepted and $\mathrm{N}_{\mathrm{D}}$ or $\mathrm{N}_{\mathrm{N}}$ each excepted in about half of the correlations. $N_{D}$ and $N_{N}$ each enter significant correlations with only five other measures, and $\mathrm{L}$ enters no significant correlation. The rs for IC, IF, and SC were above .80 . The $r$ for $f_{p} N_{D}$ was -.83 , but this reflects the partial interdependence of the two measures.

The $\mathrm{r}$ of .70 for MC is essentially the same as the SS $r$ of .704, and larger than the PYM r of .56. The I of .55 for MS is essentially the same as the SS of .564 . The $r$ of .87 for CS is above the SS r of .63. The rs for MP, SP, and CP here are two times or more the comparable SS rs. The $\mathrm{r}$ of .68 for MI is slightly below the PYM r for .72, and the $r$ of .83 for IC is identical with the PYM $r$. The rs involving $\mathrm{L}$ are all less than the comparable SS rs.

The matrix of Table 2 was factored by the principal-components model with rotation of different number of factors, and by the produced by similar mechanisms. The principal-factors model with rotation of six factors. Table 3 shows the rotated matrix of principal components that seems most

\section{Illusions, aftereffects and iconic memory}

HADYN D. ELLIS, University of Reading, Whiteknights, Reading, England

Twenty Ss viewed the Zöllner and Hering illusions under conditions involving a temporal displacement of background and parallel lines. Both illusions persisted until the disparity reached about $1 / 2 \mathrm{sec}$. It was tentatively argued that these results may be interpreted as support for the notion that illusions and aftereffects are results are also considered in terms of iconic storage.

One of the essential differences between geometrical illusions and figural aftereffects is that the former involves simultaneous presentation, whereas the latter is produced as a result of prolonged inspection of a distorting figure. Ganz (1966) has suggested that figural aftereffects and simultaneous geometrical illusions may well be mediated by the same cortical processes. This view, which is supported by Wallace (1969), embraces lateral inhibition at a central level as a possible cause.

The theory concerning the similarity of the two visual phenomena was graduate fellow. I figure. be computed. descriptive of the pattern of correlations of Table 2. The component that contributes most to total variance, labeled $C, S$, is comprised of $I, C$, and $S$ with larger loadings for $C$ and $S$. $f_{p}, N_{D}$ constitute another component. $L, N_{N}, M$, and $P$ each stand alone with relatively little contribution to total variance. The remaining component, labeled $F$, is comprised of $I$ and $F$. The more important features of the patterns of correlations and of components and loadings are the relatively large number of seemingly independent components and allocation of $I$ partly to an $S, C$ component and partly to an $F$ component.

\section{REFERENCES}

BREED, R. S. (Ed.) Bergey's manual of determinative bacteriology. ( 6 th ed.) Baltimore: Williams \& Wilkins, 1948.

PAIVIO, A., YUILLE, J. D., \& MADIGAN, S. A. Concreteness, imagery, and meaningfulness values for 925 nouns. Journal of Experimental Psychology Monograph, 1968, 76, No. 1, Part 2.

SPREEN, O., \& SCHULZ, R. W., Parameters of abstraction, meaningfulness, and pronunciability for 329 nouns. Joumal of Verbal Learning \& Verbal Behavior, 1966, 5 , 459468.

NOTE

1. Partially supported by USPHS Grant MH 13531 to Albert E. Goss, this research was done during Barry Loigman's tenure as an NDEA

strengthened by an experiment performed by Ganz (1964), in which "figural aftereffects" were produced when the inspection (I) figure and test (T) figure were presented together in time and yet produced the same sort of effects on the $T$ figure as those elicited when it was presented after prolonged inspection of the

The following experiment involved the reciprocal of Ganz's experimental paradigm. That is, two geometrical illusions, the Zöllner and Hering (Fig. 1), were presented to Ss in a manner allowing. the background (or I) figure to precede the parallel lines ( $T$ figure) so that the maximum temporal separation that still allowed a distortion of the $\mathrm{T}$ figure might

This procedure is not only reminiscent of those employed in figural aftereffect studies, but is, to some extent, similar to that used by Haber \& Standing (1969) in their quest to find a pure, sensory measure of iconic memory (Neisser, 1967). Their study involved repeated presentations of a black circle while the time between presentations was altered, according to the method of limits, so that a persistence threshold was obtained (i.e., the maximum 
separation of presentations that led to the phenomenal report that the circle was always in view). They found that up to separations of 320-340 msec (depending on illumination), Ss reported the continuous presence of a circle. These figures are similar to other reports concerning visual persistence (Sperling, 1960; Averbach \& Coriell, 1961; Parks, 1965).

By analogy, the present study traces the temporal persistence of a disrupting figure following its removal from view.

\section{SUBJECTS}

Twenty undergraduates, graduates, and staff of the University of Reading, most of whom were familiar with the illusions, acted as unpaid Ss.

\section{APPARATUS}

The stimuli were drawn in black ink on white cards $(6 \times 4$ in.) with lines of $1-\mathrm{mm}$ thickness. The cards were displayed via a three-field tachistoscope (Electronic Developments), with luminance set at $1.3 \log \mathrm{ft}-\mathrm{L}$ in each field. The background to the Zöllner was arranged to permit near-maximum effect by making the angles of intersection with the parallel lines equal to $15 \mathrm{deg}$, while the lines themselves were spaced at $5-\mathrm{mm}$ intervals (Wallace \& Crampin, 1969). There is no equivalent information in the literature concerning the Hering illusion and so may not have been drawn to give optimal distortion.

\section{PROCEDURE}

Half of the Ss were confronted first with the Zöllner illusion and then by the Hering illusion, and vice versa. Prior to each, Ss were shown completed illusions (background and parallel lines together) for $100 \mathrm{msec}$ and were then allowed to see the parallel lines alone for $100 \mathrm{msec}$. Subsequently, Ss were allowed to administer the stimuli to themselves on a command from $\mathrm{E}$, who altered the time interval between I (background) and $T$ (parallel lines) figures in steps of $10 \mathrm{msec}$.

The $I$ and $T$ figures were each shown for $100 \mathrm{msec}$, and the interval between them increased or decreased until an approximate threshold was obtained. Thereafter, a staircase method (Cornsweet, 1962) was employed for a further 15 trials to establish a more reliable threshold. More conventional methods, which take more time, were precluded because illusions show decrements with practice (see Dewar, 1967), which would have added further variance.

\section{RESULTS AND DISCUSSION}

The results may be seen in Table 1. Both illusions occur with a separation of $I$ and $T$ figures up to approximately $1 / 2 \mathrm{sec}$. The means in both cases are highly significant (Hering, $\mathrm{t}=12.13, \mathrm{df}=19, \mathrm{p}<.001$; Zöllner, $\mathrm{t}=8.66, \mathrm{df}=19, \mathrm{p}<.001$ ), but there is no difference between the means of the two illusions according to Sandler's

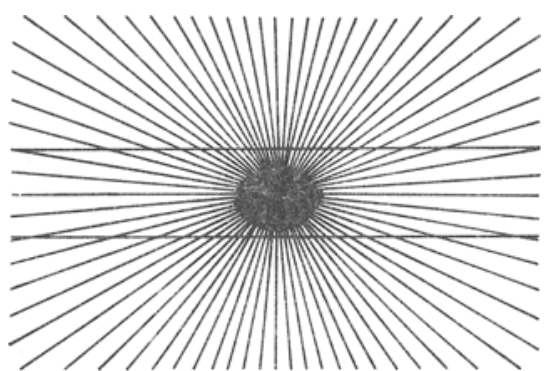

\section{Zoollner Illusion}

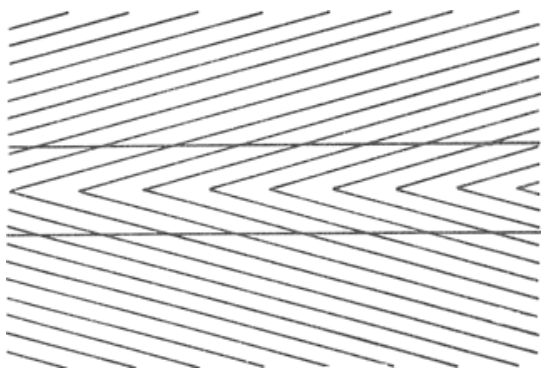

\section{Hering Illusion}

A test $(A=3.299)$, while the rank correlation between them is +0.223 , which also fails to achieve statistical significance $(t=1.022, \quad d f=18)$. The standard deviations in both cases are high and reflect at least four sources of variance: (a) individual differences in susceptibility to illusions, (b) different criteria of "parallelism," (c) differences in length of icon, and (d) the variance resulting from using an inexact method of threshold measurement.

Nevertheless, the results clearly indicate that the Zöllner and Hering illusions do not require simultaneous presentation of background and parallel lines in order for a distortion of the latter to occur. It should be noted, also, that many $S$ s volunteered the information that the magnitude of the illusion decreased in an exponential-like fashion as the interval between $I$ and $T$ increased from 0 to $500 \mathrm{msec}$, a decaying that is observable in Sperling's (1960) results.

The derived decay time of $1 / 2 \mathrm{sec}$ is higher than that found by Haber \& Standing (1969) but is well within the $1 \mathrm{sec}$ proposed by Sperling (1960) to be the length of iconic storage.

It is proposed that afterimages may be discounted as a contributory factor because, first, the interval between $I$ and $T$ figures was bright and, second, the investigations of Day (1961) and Schiller \& Table 1

Indicating Mean, Median, and Standard Deviations of Persistance for Two Illusions

\begin{tabular}{lll}
\hline & \multicolumn{1}{c}{ Zollner } & \multicolumn{1}{c}{ Hering } \\
\hline Mean & $529.25 \mathrm{msec}$ & $504.25 \mathrm{msec}$ \\
Median & $487.5 \mathrm{msec}$ & $480.0 \mathrm{msec}$ \\
SD between Ss & $273.28 \mathrm{msec}$ & $184.5 \mathrm{msec}$ \\
\hline
\end{tabular}

Fig. 1.

Wiener (1962), involving stereoscopic presentations of geometrical illusions, clearly point to a central, rather than peripheral, cause of distortion.

The tentative conclusions that have been drawn from these results involve the possibility that illusions, aftereffects, and iconic storage are all intricately related. This generalization must, however, await more substantial empirical support. One possible means of separating the three components would be to increase the I time from, say, 50 to $150 \mathrm{msec}$ and observe the effect on icon duration. Interestingly, figural aftereffect studies indicate that the effect should be enhanced (Taylor, 1962), whereas Mackworth's study of short-term visual memory (1963) suggests that increasing exposure time over that period should have little consequence upon icon duration.

\section{REFERENCES}

AVERBACH, E., \& CORIELL, A. S. Short term memory in vision. Bell Systems Technical Joumal, 1961, 40, 309-328.

CORNSWEET, T. N. The staircase method in psychophysics. American Journal of Psychology, 1962, 75, 485-491.

DAY, R. H. On the stereoscopic observation of geometrical illusions. Perceptual \& Motor Skills, 1961, 13, 247-258.

DEWAR, R. E., Stimulus determinants of the practice decrement of the Mueller-Lyer Illusion. Canadian Journal of Psychology, 1967, 21, 504-520.

GANZ, L. Lateral inhibition and the location of visual contours: An analysis of figural aftereffects. Vision Research, 1964, 4, 465-481.

GANZ, L. Mechanism of the figural aftereffect. Psychological Review, 1966, 73, 128-150.

HABER, R. N., \& STANDING, L. G. Direct measures of short-term visual storage. Quarterly Journal of Experimental Psychology, 1969, 21, 43-54.

MACKWORTH, J. F. The duration of the visual image. Canadian Journal of Psychology, 1963, $17,62-81$.

NEISSER, U. Cognitive psychology. New York: Appleton-Century-Crofts, 1967.

PARKS, T. E. Post retinal visual storage. American Joumal of Psychology, 1965, 78 145-147.

SANDLER, J. A. A test of the significance of difference between the means of correlated measures based on a simplification of student's t. British Journal of Psychology, $1955,46,225-226$.

SCHILLER, P., \& WIENER, M. Binocular and stereoscopic viewing of geometrical illusions. Perceptual \& Motor Skills, 1962, 15, 739-747.

SPERLING, G. The information available in brief visual presentations. Psychological Monographs, 1960, 74(11, Whole No. 498).

TAYLOR, M. M. Figural aftereffects: A psychophysical theory of the displacement effect. Canadian Journal of Psychology, 1962, 16, 247-277.

WALLACE, G. K. The critical distance of interaction in the Zöllner illusion. Perception \& Psychophysics, 1969, 5, 261-264.

WALLACE, G. K., \& CARMPIN, D. J. The effect of background density on the Zöllner illusion. Vision Research, 1969, 9, 167-177. 